\title{
POTENTIAL OF BIOINVASION BY HUMAN ACTIVITIES IN THE ANTARCTIC MARINE ENVIRONMENT
}

http://dx.doi.org/10.4322/apa.2014.110

\section{Bruna Rachel Rocha*, Ana Carolina Fortes Bastos, Andrea de Oliveira Ribeiro Junqueira}

Instituto de Biologia, Universidade Federal do Rio de Janeiro - UFRJ, Av. Carlos Chagas Filho, 373, CCS, bloco A, sala 089, Ilha do Fundão, CEP 21941-902, Rio de Janeiro, RJ, Brazil

*e-mail: rochabruna2@gmail.com

\begin{abstract}
Expansion of human activities increases the likelihood of species introductions in Antarctica. Considering this fact we studied the main vectors and pathways of potential introductions in the King George Island. Three main areas of human activities were considered: tourism, fishing and scientific research. We conducted a literature review and a survey of statistical data on sites of human activities in Antarctica. We observed that the transport of people and goods by human activities increased during the period under analysis. The places most visited by tourists on King George Island were scientific stations. The routes taken by several types of cruises departed mainly from ports located in Chile and Argentina. So, there is a greater likelihood of possible introductions of alien species from southern South America. The scientific stations Bellingshausen, President Eduardo Frei and Henryk Arctowski are the oldest in operation; they must be targets of investigation for a possible presence of non-native species, since time and human activities are essential factors in the processes of bioinvasion. The increase of licensed vessels and trawlers on King George Island, also enhances the risk of possible introductions of species in the marine environment. Therefore, this study is important to make inferences about the presence of introduced species besides contributing to avoid possible future introductions in the Antarctic marine environment.
\end{abstract}

Keywords: King George Island, Marine Introduction, Human Activities

\section{Introduction}

The Southern Ocean is considered one of the planet's largest natural laboratories regarding the effects of environmental change on ecosystems, communities, populations, organisms at different spatial and temporal scales. Its high degree of endemism (Griffiths et al., 2010) caused by a long period of geographic isolation, makes Antarctica an important target of research and scientific discussions, resulting in a better understanding of its ecological diversity.

However, the warming of the Southern Ocean, detected in the Antarctic Peninsula (Meredith \& King, 2005), has physiological relevance, since the Antarctic marine fauna appears to be particularly sensitive to small changes in water temperature (Peck, 2005; Barnes \& Peck, 2008; Peck et al., 2008, 2009). The effects generated by global changes associated with human activities, can influence synergistically the potential for dispersal of species, and lead to considerable structural changes in marine communities (Tin et al., 2009). In this context, biological invasion by non native species should be considered a critical impact, especially in isolated ecosystems like the Southern Ocean.

Therefore, research aimed at reducing the potential bioinvasion is critical to maintaining the intrinsic characteristics of pristine communities, such as the Antarctic marine environment. These studies need to combine human activities and its routes to generate management guidelines to decrease the potential invasions of species from outside the Antarctic continent, and also between different biogeographic regions inside Antarctica and thus prevent the break of regional endemism causing the consequent loss of genetic distinction between these locations. So the goals of this study have been to understand the main routes related to human activities (scientific 


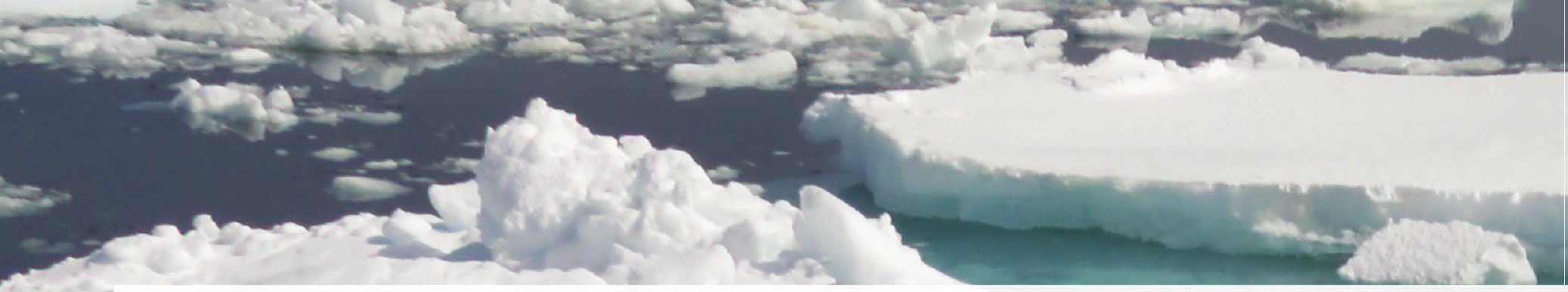

research, tourism and fishing) in Antarctica and identify the locations in King George Island which are more susceptible to invasions of exotic species.

\section{Materials and Methods}

We studied the main vectors and pathways of potential introductions in King George Island. Thus, three main areas of human activities were considered: tourism, fishing and scientific research. We conducted a literature review and a survey of statistical data on sites of human activities in Antarctica. We surveyed the tourism activity on King George Island: the places most visited by tourists, their nationality, the ports of departure, the types of vessels used for this activity and the recommendations transmitted to the tourists to reduce the impact of visitation and the likelihood of introduction of species. This data was surveyed on IAATO site (International Association of Antarctica Tour Operators). We also investigated the amount of scientific research: the existing stations and shelters on King George Island and the countries involved in the operation of these stations and the ports where scientists travel to Antarctica. Investigations about fishing activities were also undertaken, because it is another important vector of non intentional introduction, especially related to marine ecosystems.
Related data was reviewed on CCAMLR site (Convention for the Conservation of Antarctic Marine Living Resource).

\section{Results}

The tourist season occurs during the austral summer, Antarctic visits are mainly concentrated at ice-free coastal zones over the five month period from November to March. According to data published by the IAATO and compiled by SCAR KGIS (Scientific Committee on Antarctic Research, King George Island) there are 21 main points of tourist visitation in King George Island: 1-Cape Melville, 2- Turrent Point, 3-Penguin Island, 4-Lion`s Rump, 5-King George Island, 6-Comandante Ferraz (Brazil), 7-Martel Inlet, 8-Admiralty Bay, 9-Henryk Arctowski (Poland), 10-Point Thomas, 11-Ezcurra Inlet, 12-Potter Cove, 13- Carlini (Argentina), 14-King Sejong (Korea), 15- Maxwell Bay, 16-Artigas (Uruguay), 17-Ardley Island, 18-Fildes Peninsula, 19-Bellingshausen (Russia), 20- President Eduardo Frei (Chile) and 21- Great Wall (China).

During the period from 2007 to 2010, the places most visited by tourists on King George Island were mainly the Henryk Arctowski station (Poland), followed by Penguin Island and the President Eduardo Frei of Chile station (Figure 1).

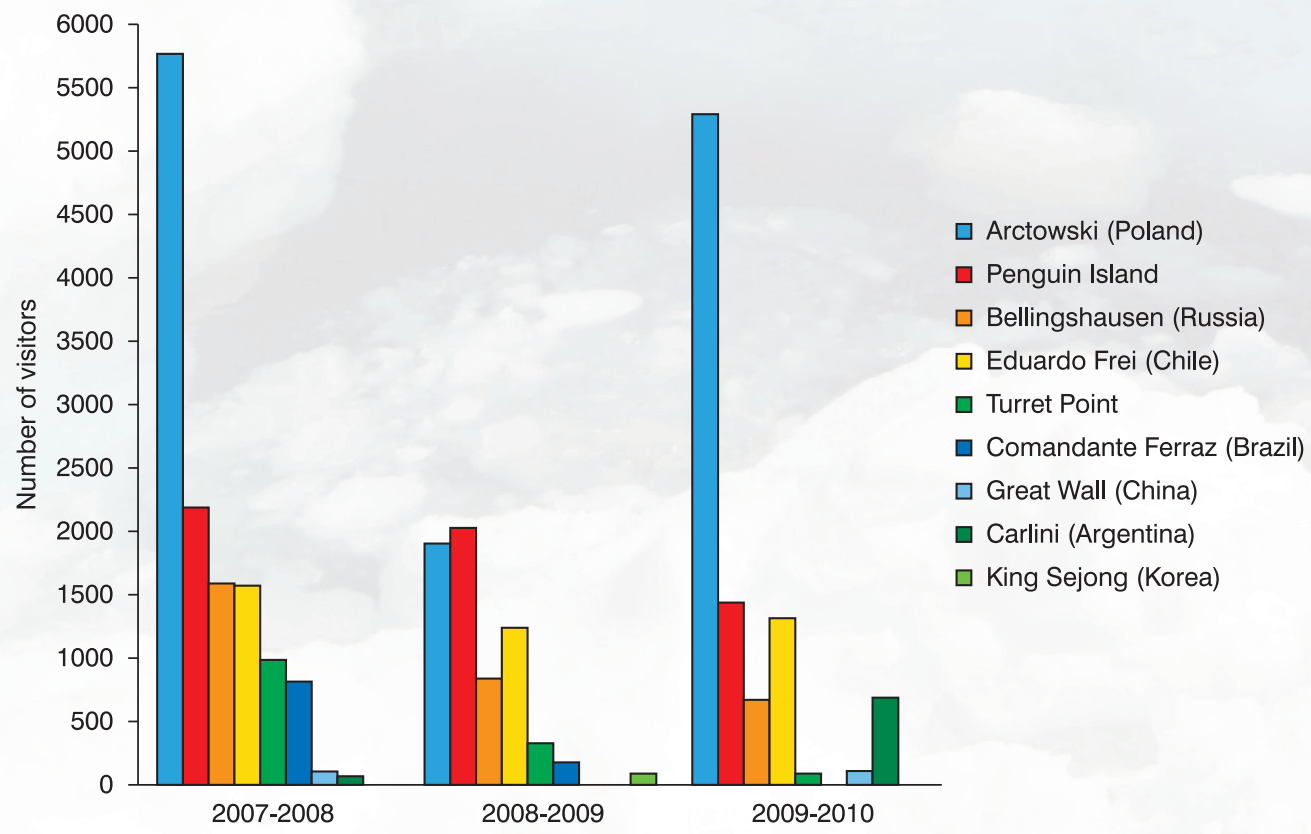

Figure 1. Number of visitors in the main points of tourist visitation on King George Island. Source: IAATO, 2011. 
According to IAATO, the cruises are carried out by some 40 vessels each carrying from 6 to 500 tourists. The vessels sail primarily to the Antarctic Peninsula region. Occasional voyages to Antarctica also have included larger passenger vessels carrying from 500 to 3.000 tourists. Most cruises depart from one of the ports in southern South America, such as Ushuaia (Argentina), Punta Arenas (Chile) or Montevideo (Uruguay) to the Antarctic Peninsula. These cruises often include visits to the nearby Falkland Islands and South Georgia.

During the period from 2007 to 2010, tourists that visited Antarctica came mainly from: United States, Germany and United Kingdom. Despite the proximity of the Antarctic continent to South America, none of the major nationalities who visited the Antarctic came from countries of South America (Figure 2).

According to IAATO, the boots, clothing and equipment must be cleaned with running water for decontamination before and after of landing. Clothing and equipment have to be checked thoroughly by a member of the ship's crew or staff. The main recommendations provided to tourists are to protect Antarctic wildlife, respect protected areas, respect scientific research, be safe and keep Antarctica pristine.

Regarding the scientific bases, there are permanent bases (that work throughout the year) and seasonal ones (which work only during summer) are scattered mainly in the southwestern region of King George Island closer to Bransfield Strait. The scientific bases are located at points of the island where the soil is exposed during the summer through melting.

The permanent stations are: 1) Argentina: Carlini; 2) Brazil: Comandante Ferraz, 3) Chile: President Eduardo Frei, 4) Chile: Professor Julio Escudeiro, 5) China: Great Wall, 6) Korea: King Sejong, 7) Poland: Henryk Arctowski, 8) Russia: Bellingshausen, 9) Uruguay: Artigas. Other countries have the following temporary stations: 1) Peru: Machu Picchu, 2) Germany: Dallmann Laboratory. Russia, Brazil, Korea, Argentina, United States, Poland and Ecuador have also full and temporary shelters in King George Island. The Bellingshausen (Russia), President Eduardo Frei (Chile) and Henryk Arctowski (Poland) stations are the oldest in operation on King George Island, with 42, 41 and 33 years of age respectively.

According to Frenot et al. (2005), the routes taken by the researchers conducting scientific activities in King George Island leave from the following countries and ports: 1) Argentina: Buenos Aires, El Palomar, Mar del Plata and Ushaia; 2) Brazil: Rio de Janeiro and Punta Arenas; 4) Chile: Valparaiso; 5) China: Shanghai; 6) Germany: Bremerhaven;

7) Korea: Ulsan; 8) Poland: Gdynia; 9) Russia: St Petersburg; 10) Uruguay: Montevideo.

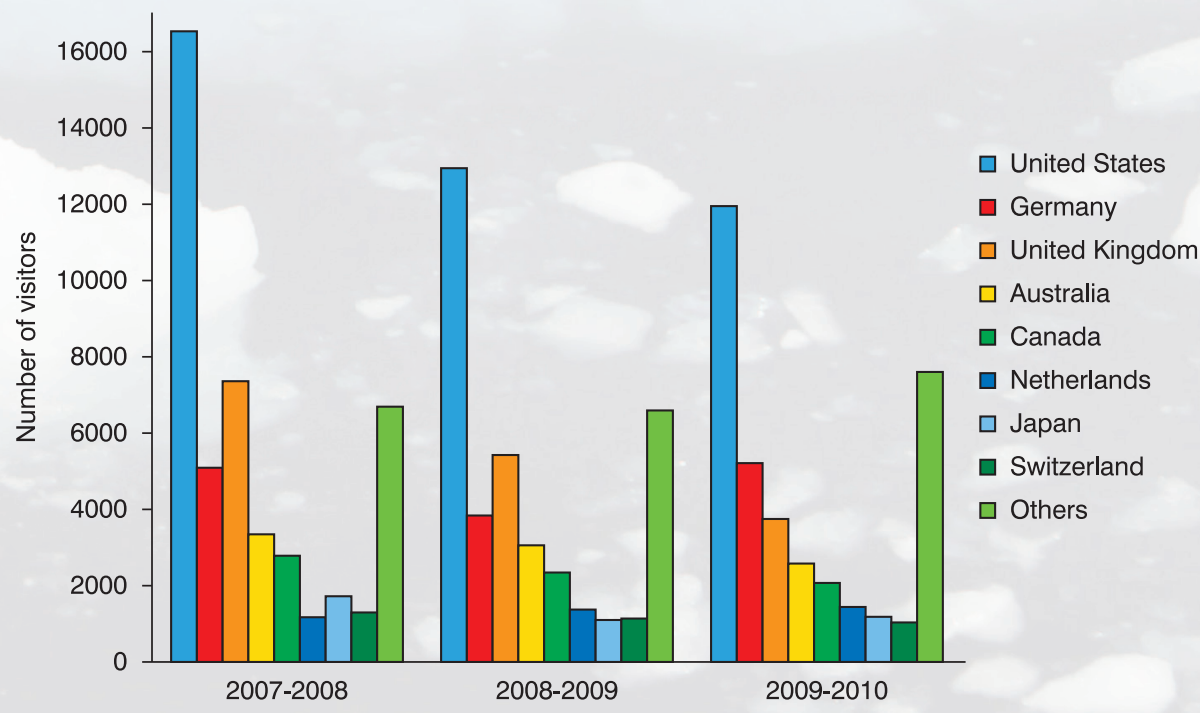

Figure 2. Number of visitors by nationality in Antarctica. Source: IAATO, 2011. 


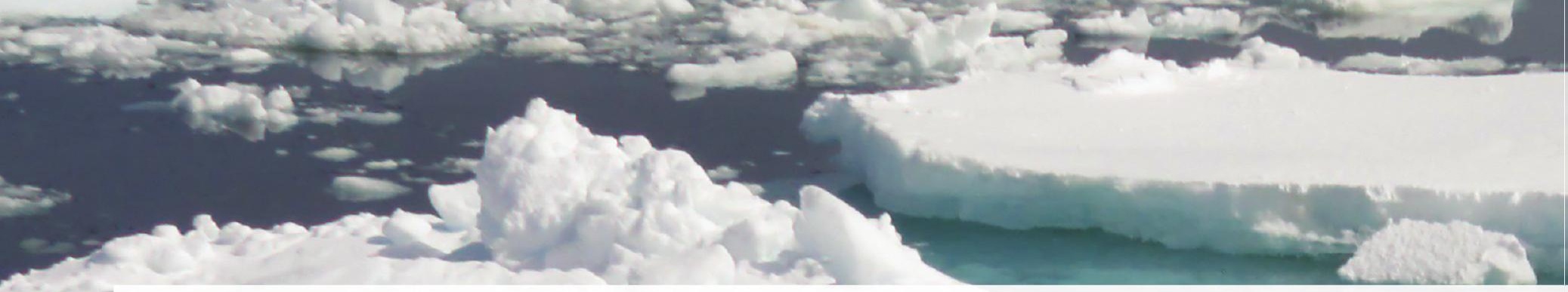

CCAMLR has adopted the same divisions of fishing areas used by FAO (Food and Agriculture Organization of the United Nations). In the Southern Ocean, three fishing areas are located, as follows: 88 (Pacific, Antarctic), 48 (Atlantic, Antarctic) and 58 (Antarctic and Southern Indian Ocean). Fishing area 48 is divided into six sub-areas: 48.1-Peninsular, 48.2-South Orkney, 48.3-South Georgia, 48.4-South Sandwich, 48.5-Weddel Sea and 48.6-Bouvet. King George Island is located in sub-area 48.1 as well as all the Antarctic Peninsula.

According to CCAMLR, the targets of fishery at three areas located in the Southern Ocean are: Champsocephalus gunnari, Lithodidae, Euphausia superba, Myctophids, Rajiformes, Dissostichus eleginoides and Dissostichus spp. During the period from 2008 to 2012 in sub-area 48.1, only the species Euphausia superba (Antarctic krill) was target of fishery and all licensed vessels used trawling gear for fishing. The number of vessels during this period was 2008/2009 - 9, 2009/2010- 11, 2010/2011 - 13 and 2011/2012 -13. Most of these vessels came from: Chile, China, Japan, Norway, Korea and Poland.

\section{Discussion}

We highlight the scientific stations as main tourist places on King George Island, because of the infrastructure which facilitates the landing of the tourists and are also major attractions for visitors. Therefore, the most visited places are more likely to suffer introductions of species (Frenot et al., 2005; IAATO, 2011). The routes taken by vessels of tour operators depart mainly from ports located in Chile and Argentina or ports located in regions such as Stanley in the Falkland Islands. According to Frenot et al. (2005), the only exception would be the port of Bluff in New Zealand. Thus, there is a greater likelihood of unintentional introductions of species from southern South America. Bellingshausen (Russia), President Eduardo Frei (Chile) and Henryk Arctowski (Poland) bases are the oldest in operation. This means that both the pathways and vectors used by these stations, must be targets of investigation for a possible presence of non-native species, since time and human activities are essential factors in the processes of bioinvasion. In addition, the bases are distributed mainly near the Strait of Bransfield, so this region should be a priority target for research on bioinvasion.

The increase of licensed vessels for fishing over the years in the subarea 48.1, where King George Island is located, enhances the risk of possible introductions in this region. Thus, it is important to study the routes of these vessels from the port of origin to their areas of fishing activities within the Southern Ocean. Furthermore, the licensed vessels for fishery in sub-area 48.1 also carry out activities in other sub-areas and in other fishing areas of Antarctica (area 58), which may contribute to the dispersal of species between different areas of endemism. In addition, trawlers may be possible vectors of introduction of alien species in the Antarctic marine environment.

\section{Conclusion}

The transport of people and goods are increasing as a result of human activities (tourism, fishing and scientific research) at King George Island as demonstrated in this study. Therefore, the study of the main vectors and pathways as well as of the most vulnerable places is essential before making inferences about the presence of introduced species in the Antarctic marine environment. It also contributes to avoiding possible future introductions.

\section{Acknowledgments}

This work integrates the National Institute of Science and Technology Antarctic Environmental Research (INCTAPA) that receives scientific and financial support from the National Council for Research and Development (CNPq process: $n^{\circ}$ 574018/2008-5) and Carlos Chagas Research Support Foundation of the State of Rio de Janeiro (FAPERJ $\left.\mathrm{n}^{\circ} \mathrm{E}-16 / 170.023 / 2008\right)$. The authors also acknowledge the support of the Brazilian Ministries of Science, Technology and Innovation (MCTI), of Environment (MMA) and Inter-Ministry Commission for Sea Resources (CIRM). 


\section{References}

Barnes, D.K.A. \& Peck, L.S. (2008). Examining vulnerability of Antarctic shelf biodiversity to predicted climate warming. Climate Research, 37:149-163.

Convention on the Conservation of Antarctic Marine Living - CCAMLR. Available from: <http://www.ccamlr.org/pu/e/genintro.htm >. Consulted on 2012-01-16.

Frenot, Y.; Chown, L.S.; Whinam, J.; Selkirk, P. M.; Convey, P.; Skotnicki, M. \& Bergstrom, D.M. (2005). Biological invasions in the Antartic: extent, impacts and implications. Biological Reviews, 80:45-72.

Griffiths, H. J. (2010). Antarctic Marine Biodiversity - What Do We Know About the Distribution of Life in the Southern Ocean? PLOS ONE 5(8): e11683. http://dx.doi.org/10.1371/journal.pone.0011683

International Association of Antarctica Tour Operators - IAATO. Available from: <www.iaato.org/tourism overview.html>. Consulted on 2011-03-14.

Meredith, M.P. \& King, J.C. (2005). Rapid climate change in the ocean west of the Antarctic Peninsula during the second half of the 20th century.Geophysical Research Letters, 32:1-5.

Peck, L.S. (2005). Prospects for survival in the Southern Ocean: vulnerability of benthic species to temperature change. Antarctic Science, 17:497-507.

Peck, L.S.; Webb, K.E.; Miller, A.; Clark, M.S. \& Hill, T. (2008). Temperature limits to activity, feeding and metabolism in the Antarctic starfish Odontaster validus. Marine Ecology Progress Series, 358:181-189.

Peck, L.S.; Clark, M.S.; Morley, S.A.; Massey, A. \& Rossetti, H. (2009). Animal temperature limits and ecological relevance: effects of size, activity and rates of change. Functional Ecology, 23:248-256.

Tin, T.; Fleming, Z.L.; Hughes, K.A; Ainley, D.G.; Convey, P.; Moreno, C.A.; Pfeiffer, S.; Scott, J. \& Snape, I. (2009). Impacts of local human activities on the Antartic environment. Antartic Science, 21(1):3-33. 